\title{
ДОСУДЕБНЫЙ ПОРЯДОК РАЗРЕШЕНИЯ ИНДИВИДУАЛЬНЫХ ТРУДОВЫХ СПОРОВ В СФЕРЕ СПОРТА: СОСТОЯНИЕ И ТЕНДЕНЦИИ РАЗВИТИЯ
}

\author{
А. А. Бредихин \\ Национальный исследовательский университет \\ "Высшая школа экономики" \\ Поступила в редакцию 4 июня 2019 г.
}

\begin{abstract}
Аннотация: расслатривается состояние организационно-правового обеспечения досудебного урегулирования индивидуальных трудовых споров в сфьре спорта. Выдвигается тезис, что в индивидуальных трудовых спорах в сфбере спорта пострадавшая сторона обрашается за зашитой своих прав в юрисдикиионный орган спортивной фьедерации по соответствующему виду спорта. Автор подвергает анализу правовую модель института разрешения индивидуальных трудовых споров в собере спорта, в ходе которого ставится вопрос, праволерно ли квалифииировать юрисдикиионные органы спортивных фбедераций в качестве комиссий по трудовылм спорал. Автор обращает внимание на коллизии и пробель в данной области права, а также предлагает внесение соответствующих изменений в трудовое и спортивное законодательство.
\end{abstract}

Ключевые слова: индивидуальные трудовые споры, спорт, трудовой договор, колиссии по трудовыли спорал.

\begin{abstract}
: discusses the establishment of the organizational and legal support of pre-trial settlement of individual labor disputes in the field of sports. The thesis is advanced that, as a rule, in individual labor disputes in the field of sports, the injured party applies for the protection of their rights to the jurisdictional authority of the sports federation for the relevant sport. The author analyzes the legal model of the institute for the resolution of individual labor disputes in the field of sports, during which the question is raised whether the jurisdictional bodies of sports federations can be qualified as commissions for labor disputes. Finally, in order to eliminate the conflicts and gaps in the law, it is proposed to introduce appropriate changes in the labor and sports legislation.
\end{abstract}

Key words: individual labor disputes, sport, employment contract, labor dispute committee.

На современном этапе развития спортивного законодательства Российской Федерации весьма актуальным является усовершенствование института разрешения трудовых споров в сфере спорта, поскольку каждый участник таких общественных отношений должен иметь реальную, предусмотренную законом, возможность защиты своих трудовых прав, о чем также указано в Концепции федеральной целевой программы «Развитие физической культуры и спорта в Российской Федерации на 20162020 годы» ${ }^{1}$, Государственной программе Российской Федерации «Разви-

${ }^{1}$ Об утверждении Концепции фредеральной целевой программы «Развитие физической культуры и спорта в Российской Федерации на 2016-2020 годы» : рас-

(C) Бредихин А. А., 2021 
тие фозической культуры и спорта» ${ }^{2}$ и Стратегии развития фозической культуры и спорта в Российской Федерации на период до 2020 г. ${ }^{3}$ Сводные отчеты свидетельствуют о том, что в России число штатных работников физической культуры и спорта составляет примерно 383845 человек ${ }^{4}$. Управление человеческим капиталом в современном спорте может быть достигнуто посредством обеспечения эфрфективного правового регулирования сферы трудовых отношений и предоставления действенного механизма разрешения трудовых споров с учетом специфики спорта, поскольку среди спортивных споров более половины относятся именно к вопросам трудовых правоотношений.

Российским трудовым законодательством установлен закрытый перечень органов по рассмотрению индивидуальных трудовых споров, куда входят комиссии по трудовым спорам и суды (ст. 382 ТК РФ). В то же время глава 54.1. ТК РФ, регулирующая трудовые отношения с участием спортсменов и тренеров, не содержит правовых норм, предусматривающих возможность обращения с целью защиты трудовых прав в иной орган. На наш взгляд, данное обстоятельство свидетельствует о несовершенстве правовой модели разрешения споров в сфере спорта.

Вообще, так называемой сердцевиной данной правовой модели можно считать нормы саморегулирования в сфере спорта (например, устав общероссийской спортивной федерации), действующие на основе принципа сочетания государственного регулирования отношений в области фризической культуры и спорта с саморегулированием таких отношений субъектами физической культуры и спорта в соответствии с п. 3 ст. 3 Федерального закона от 4 декабря 2007 г. № 329-ФЗ «О физической культуре и спорте в Российской Федерации» (далее - Закон о спорте). Данные нормы регламентируют правовой статус юрисдикционных органов спортивных федераций (профессиональной спортивной лиги), наделяя их полномочиями по рассмотрению и разрешению споров в сфере спорта. В частности, М. А. Погорелов в одной из своих работ утверждает, что в сыере спорта сформировался самостоятельный механизм разрешения споров через дисциплинарные комитеты и палаты по разрешению споров 5 .

поряжение Правительства РФ от 2 января 2014 г. № 2-р // Собр. законодательства Рос. Федерации. 2014. № 2 (ч. 2). Ст. 229.

${ }^{2}$ Об утверждении Государственной программы Российской Федерации «Развитие фризической культуры и спорта» : постановление Правительства РФ от 15 апреля 2014 г. № 302 // Собр. законодательства Рос. Федерации. 2014. № 18 (ч. 1). Ст. 2151.

${ }^{3}$ Об утверждении Стратегии развития физической культуры и спорта в Российской Федерации на период до 2020 года : распоряжение Правительства РФ от 7 августа 2009 г. № 1101-р // Собр. законодательства Рос. Федерации. 2009. № 33. Ст. 4110.

${ }^{4}$ Сводный отчет по форме федерального статистического наблюдения № 1-ФК «Сведения о физической культуре и спорте» за 2018 год. URL: https://www.minsport. gov.ru/2019/doc/Svodnii-otshet-1fk-za_2018.xls (дата обращения: 20.05.2019).

${ }^{5}$ См.: Погорелов M. A. Медиация как альтернативный способ разрешения конфликтов с участием спортсменов и тренеров // Пятая международная науч- 
Применительно к индивидуальным трудовым спорам в сфере фрутбола, например, учрежден юрисдикционный орган Российского футбольного союза (далее - РФС) - Палата РФС по разрешению споров, который в соответствии с регламентными нормами данной общероссийской спортивной федерации имеет право рассматривать и разрешать трудовые споры ${ }^{6}$. В сфере хоккея трудовые споры имеет право рассматривать и разрешать Дисциплинарный комитет КХЛ ${ }^{7}$. Однако в сфере баскетбола и волейбола таких юрисдикционных органов пока не существует, поэтому пострадавшая сторона в данных видах спорта вынуждена обращаться в суд общей юрисдикции либо в комиссию по трудовым спорам для защиты своих трудовых прав в соответствии со ст. 382 ТК РФ.

Согласимся с теми спортивными юристами, которые отмечают преимущество юрисдикцинных органов спортивных федераций перед судами общей юрисдикции относительно эффективности рассмотрения споров в сфере спорта (включая трудовые) ${ }^{8}$. В связи с этим очевидно, что арбитры юрисдикционных органов спортивных федераций имеют глубокие познания в спортивном праве, что позволяет им выносить справедливые и исполнимые решения, учитывая специфику спорта. Под последним следует понимать то, что решение, вынесенное юрисдикционным органом спортивной федерации, приводится в исполнение с использованием специальных негосударственных механизмов принуждения, а именно: снятие турнирных очков, запрет на регистрацию новых спортсменов для участия в соревновании, дисквалификация от участия в соревновании и т. д. Применительно к процессуальным преимуществам отметим точку зрения Д. И. Рогачёва и Ю. В. Зайцева, обращающих внимание на то, что в юрисдикционных органах спортивных федераций могут быть установлены более длительные сроки для обращения спортсмена или тренера за защитой нарушенных прав. Например, срок обращения в юрисдикционный орган РФС составляет два года ${ }^{9}$, в то время как общий срок исковой давности по индивидуальным трудовым спорам составляет три месяца (ст. 392 ТК РФ).

Целесообразно отметить вывод Е. В. Погосяна о том, что «спортсмены заинтересованы в том, чтобы спор между ними был разрешен лицом, об-

но-практическая конференция «Спортивное право : перспективы развития» : материалы конференции / под общ. ред. К. Н. Гусова, А. А. Соловьёва ; сост. Д. И. Рогачёв, О. А. Шевченко. М., 2011. С. 117.

${ }^{6}$ См.: Часть 1 ст. 13 Регламента РФС по разрешению споров. URL: https:// static.rfs.ru/documents/1/5acf953b0a29f.doc (дата обращения: 20.05.2019).

${ }^{7}$ См.: Часть 3 ст. 35 Дисциплинарного регламента КХЛ. URL: https://www. khl.ru/documents/KHL_disciplinary_regulations_2018.pdf (дата обращения: 20.05.2019).

${ }^{8}$ См.: Прокопеи М. А., Рогачёв Д. И., Вегер Ф. Разрешение фрутбольных споров : анализ практики Палаты по разрешению споров ФИФА, РФС и Спортивного арбитражного суда (г. Лозанна). М., 2012. С. 28-29.

${ }^{9}$ См.: Зайцев Ю. В., Рогачёв Д. И. Трудовые будни в мире спорта : особенности регулирования труда спортсменов и тренеров. М., 2012. С. 40. 
ладающим специальными знаниями в сфере спорта, а потому способным учесть особенности каждой конкретной конфликтной ситуации» ${ }^{10}$.

Следует констатировать, что в спортивном законодательстве России отсутствует легальное определение термина «юрисдикиионный орган спортивной фбедерации». С. А. Юрлов в диссертационном исследовании предлагает следующую трактовку данного термина: «структурное подразделение (комитет, комиссия, совет, палата) спортивной организации (прежде всего фредерации по виду спорта), действующее на постоянной основе, состоящее из членов (судей, арбитров, членов комиссии и др.), обладающих познаниями в спорте и уполномоченное разрешать различные категории спортивных споров (дисциплинарные, допинговые, этические и др.)» ${ }^{11}$.

В то же время Д. И. Рогачёв под юрисдикционным органом понимает механизм, с помощью которого возможно разрешение спортивных споров, и обращает внимание на то, что квазисудебными указанные органы иногда именуют по той причине, что они фрактически осуществляют разрешение споров, которые относятся к компетенции судов. Исследователь приходит к выводу, что их статус законодательством никак не определен - они не являются ни третейскими судами, ни комиссиями по трудовым спорам, ни органами медиации, а основанием их деятельности служит соответствующая оговорка в регламенте, действие которого обязательно в силу акта признания регламентных норм ${ }^{12}$.

При этом судебная практика российских судов всё же признает юрисдикционные органы спортивных фредераций в качестве аналога комиссий по трудовым спорам ${ }^{13}$. В частности, по логике таких судебных решений, если какое-либо лицо обращается в суд за защитой своих прав, а регламентные нормы спортивной федерации закрепляют обязательный порядок досудебного разрешения споров в соответствующем юрисдикционном органе, то суд может отказать в принятии искового заявления ${ }^{14}$.

Следовательно, юрисдикционные органы спортивных фредераций играют неоспоримую роль в разрешении трудовых споров в сфере спорта, а отсутствие в понятийном аппарате спортивного законодательства его легального определения явным образом свидетельствует о наличии пробела в праве.

Впрочем, отечественный законодатель ввел некоторые новеллы в Закон о спорте, затрагивающие сферу института разрешения споров в обла$>$ $>$ сти спорта. Так, в 2016 г. данный закон был дополнен главой, регулиру-

${ }^{10}$ Погосян E. В. Формы разрешения спортивных споров. М., 2011. С. 59.

${ }^{11}$ Юрлов С. А. Разрешение спортивных споров : вопросы теории и практики : дис. ... канд. юрид. наук. М., 2017. С. 74.

${ }^{12}$ См.: Зайцев Ю. В., Рогачёв Д. И. Указ. соч.

13 Апелляционные определения: Омского областного суда по делу № 332142/13 ; Московского городского суда от 16 января 2014 г. по делу № 33-1073/14 ; от 24 мая 2013 г. по делу № 11-13482. Доступ из справ.-правовой системы «КонсультантПлюс».

14 Определение Московского городского суда от 26 марта 2014 г. по делу № 4г/8-2621. Доступ из справ.-правовой системы «КонсультантПлюс». 


\section{Вестник ВГУ. Серия: Право}

ющей деятельность нового третейского органа - постоянно действующего арбитражного учреждения, администрирующее арбитраж (третейское разбирательство) споров в профессиональном спорте и спорте высших достижений, включая индивидуальные трудовые споры. К компетенции данного органа было отнесено разрешение индивидуальных трудовых споров спортсменов и тренеров в профессиональном спорте и спорте высших достижений ${ }^{15}$. Но при этом возникает правовая коллизия, поскольку, как было указано ранее, ст. 382 ТК РФ наделяет правом рассмотрения индивидуальных трудовых споров всего два органа - суд и комиссию по трудовым спорам. В целях устранения данной коллизии, на наш взгляд, законодателю следует внести соответствующую поправку в ст. 382 ТК РФ в виде расширения перечня органов, имеющих право рассматривать индивидуальные трудовые споры.

Кроме того, данная новелла свидетельствует о том, что законодатель предпринял попытку создания единого третейского учреждения, рассматривающего спортивные споры во всех видах спорта, предоставляя возможность получения защиты в рамках спортивной юрисдикции тем субъектам спорта, в чьих видах спорта не созданы юрисдикционные органы спортивных фредераций. Похожие модели единых спортивных арбитражей существуют в некоторых зарубежных государствах: в Греции -

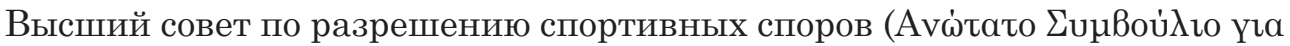

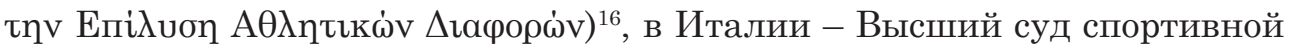
юстиции (Alta Cortedi Giustizia Sportiva) и Национальный спортивный арбитражный трибунал (Tribunale nazionale di arbitrato per lo sport e disciplina degli arbitri) ${ }^{17}$, в Канаде - Канадский центр разрешения спортивных споров (Sport Dispute Resolution Centre of Canada) ${ }^{18}$, в Мексике Комиссия по апелляциям и арбитражу в спорте (Comision de Apelacion

- y Arbitraje del Deporte $)^{19}$ и т. д. Заметим, что действующие до введения 이 новеллы Международный коммерческий арбитражный суд при ТоргоZ во-промышленной палате и Спортивный арбитражный суд «Спортивная テ арбитражная палата» не имели полномочий рассматривать индивиду尺े альные трудовые споры в сфрере спорта. Более того, ранее арбитраж мог быть сформирован на основе любого юридического лица, а в настоящее

${ }^{15}$ См.: Пункт 11 ч. 1 ст. 36.3 Федерального закона «О фризической культуре и спорте в Российской Федерации» // Собр. законодательства Рос. Федерации. 2007. № 50. Ст. 6242.

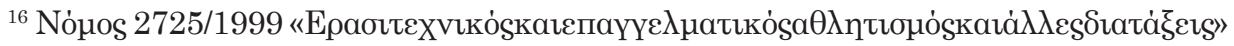
// ФEK. 121 A'/17.6.1999.

17 Decreto-Legge 19 agosto 2003, № 220 «Disposizioni urgenti in mate-ria di giustizia sportive» // GU. 20.08.2003. № 192 .

18 Physical Activity and Sport Act, 2003. URL: http://laws-lois.justice.gc.ca/eng/ acts/p-13.4/index.html (дата обращения: 20.05.2019).

${ }^{19}$ Ley General de los Estados Unidos Mexicanos de05.06.2013 de Cultura Física y Deporte // Diario Ofi cial de la Federación. 07.06.2013. Ultima reforma publicada el 9 de mayo de 2014. URL: http://www.diputados.gob.mx/LeyesBiblio/pdf/LGCFD.pdf (дата обращения: 20.05.2019). 
время третейский суд может быть создан только при некоммерческой организации, одобренной Советом по совершенствованию третейского разбирательства ${ }^{20}$.

На наш взгляд, законодатель созданием данного третейского органа стремится снизить количество апелляционных пересмотров спортивных споров в иностранных арбитражных учреждения ${ }^{21}$, например в Спортивном арбитражном суде в г. Лозанне (далее-CAS). Связано это также с экономическим фактором. В частности, пошлина за рассмотрение спора в CAS составляет 1000 швейцарских франков ${ }^{22}$ (примерно 64000 рублей).

Впрочем, в некоторых видах спорта устанавливается обязательная юрисдикция CAS в качестве органа апелляционной инстанции. Так, в сфере футбола п. 2 ст. 53 Регламента РФС по разрешению споров устанавливает, что решение Палаты РФС по разрешению споров может быть обжаловано в CAS в течение 21 дня с момента получения сторонами решения в окончательной форме по вопросам:

- о нарушении порядка заключения трудового договора между футбольным клубом и футболистом;

- нарушении условий трудовых договоров;

- нарушении условий трудовых договоров с главным тренером, тренерами, включенными в заявочный (дозаявочный) лист профессионального фотбольного клуба для участия в соревнованиях;

- нарушении условий и порядка обязательной выплаты в случае расторжения трудового договора по собственному желанию без уважительных причин, а также в случае расторжения трудового договора по инициативе профессионального футбольного клуба по основаниям, которые отнесены к дисциплинарным взысканиям, действующим трудовым законодательством Российской Федерации;

- нарушении положений о стабильности трудовых договоров в футболе.

Применительно к практическим результатам появления данной новеллы следует отметить, что постоянно действующее арбитражное учреждение, администрирующее арбитраж (третейское разбирательство) споров в профессиональном спорте и спорте высших достижений, до настоящего времени не рассмотрело ни одного спора. На наш взгляд, связано это с отсутствием регламента (устава), определяющего ключевые вопросы деятельности данного органа (порядок формирования состава, процессуальные правила рассмотрения споров, место нахождения

${ }^{20}$ Об утверждении Положения о порядке создания и деятельности Совета по совершенствованию третейского разбирательства : приказ Минюста России от 20 марта 2019 г. № 45 : зарегистрировано в Минюсте России 27 марта 2019 г. № 54183.

${ }^{21}$ См.: Часть 2 ст. 36.5 Федерального закона «О фризической культуре и спорте в Российской Федерации» // Собр. законодательства Рос. Федерации. 2007. № 50. Ст. 6242.

${ }^{22}$ См.: Статья R37 Кодекса CAS (Code of Sports-related Arbitration, in force as from 1 January 2019). URL: https:/www.tas-cas.org/fileadmin/user_upload/CAS_ Code_2019_EN_.pdf (дата обращения: 20.05.2019). 


\section{Вестник ВГУ. Серия: Право}

и т. д.). Такого же мнения придерживаются некоторые практикующие спортивные юристы ${ }^{23}$.

Впрочем, проводимая законодателем третейская редрорма всё же свидетельствует, на наш взгляд, о наличии позитивной динамики развития правовой модели разрешения споров в сфере спорта, поскольку наличие единого арбитражного учреждения в сфере спорта позволит субъектам спорта получить доступ к конфиденциальному рассмотрению споров, что также является ключевым отличием от рассмотрения таких споров в государственном суде, поскольку необходимость соблюдения конфиденциальности диктуется условиями трудовых договоров со спортсменами, их рекламными обязательствами и пр.

Обобщая информацию о текущем состоянии правовой модели досудебного порядка разрешения индивидуальных трудовых споров в сфере спорта, можно сказать, что спортивное законодательство Российской Федерации требует дальнейших доработок. Несмотря на систематические внесения изменений в Закон о спорте, отмечается несовершенство его понятийного аппарата в виде отсутствия легального определения такого термина, как «юрисдикционный орган спортивной фредерации», а также наличие правовой коллизии с ТК РФ относительно определения полномочий по рассмотрению индивидуальных трудовых споров. В связи с этим предполагаются изменения в российском законодательстве по следующим направлениям:

1. Добавление в ст. 2 Закона о спорте легального определения термина «юрисдикционный орган спортивной фредерации (профрессиональной лиги)».

2. Устранение правовой коллизии между ст. 382 ТК РФ и п. 11 ч. 1 ст. 36.3 Закона о спорте об определении компетенции органов, имеющих право рассматривать индивидуальные трудовые споры.

3. Создание регламента (устава) постоянно действующего арбитражного учреждения, администрирующего арбитраж (третейское разбирательство) споров в профессиональном спорте и спорте высших достижений.

4. Внесение в регламентные нормы и уставы общероссийских спортивных фредераций третейской оговорки, предусматривающей возможность обращения в постоянно действующее арбитражное учреждение, админи-

118 стрирующее арбитраж (третейское разбирательство) споров в профессиональном спорте и спорте высших достижений.

23 См.: Спортивный арбитраж в России : как это будет работать. URL: https://360tv.ru/news/sport/sportivnyj-arbitrazh-v-rossii-kak-eto-budet-rabotat/ (дата обращения: 20.05.2019).

Национальный исследовательский университет "Высшая школа эконолики»

Бредихин А. А., аспирант кафбедры трудового права и права социального обеспечения

E-mail: bredikhin.artem1994@gmail.com
National Research University "Higher School of Economics"

Bredikhin A. A., Post-graduate Student of the Labour Law and Social Security Law Department

E-mail: bredikhin.artem1994@gmail.com 